\title{
Outcome of clinical hypothyroidism in pregnancy: a case control study
}

\author{
John B. Lopamudra*, Rani P. Reddi, Seetesh Ghose
}

Department of Obstetrics and Gynecology, Mahatma Gandhi Medical College and Research Institute, Pondicherry

Received: 20 April 2016

Accepted: 16 May 2016

\section{*Correspondence:}

Dr. John B. Lopamudra

E-mail: drlopamdpondy@yahoo.com

Copyright: (c) the author(s), publisher and licensee Medip Academy. This is an open-access article distributed under the terms of the Creative Commons Attribution Non-Commercial License, which permits unrestricted non-commercial use, distribution, and reproduction in any medium, provided the original work is properly cited.

\begin{abstract}
Background: Hypothyroidism in pregnancy is generally associated with various adverse outcomes. Also worldwide, there is an increased awareness about morbidity caused by this endocrinological disorder in pregnancy .This study is undertaken to evaluate the outcome of this condition in pregnancy.

Methods: 144 newly diagnosed clinical hypothyroid pregnant women were taken as the case group and 145 age and parity matched euthyroid pregnant women were taken as controls. The outcome compared in between these two groups were pregnancy complications like gestational diabetes and hypertension, oligohydramnios, intrauterine growth restriction, intrauterine demise, Caesarean section rates and it's indication as well as neonatal outcome like birth weight and need for neonatal intensive care.

Results: Clinical hypothyroidism in pregnancy constituted $6.1 \%$ of the total number of deliveries. There was a significantly higher number of gestational diabetes in the case group $(\mathrm{p}=0.0001)$. Caesarean sections done for the indication of foetal distress was significantly higher when compared with the control group ( $\mathrm{p}=0.00002)$. Large for gestational age babies were more common in case group.

Conclusions: Clinical hypothyroidism in pregnancy even when treated adequately might lead to complications.
\end{abstract}

Keywords: Hypothyroidism, Pregnancy, Diabetes, Hypertension

\section{INTRODUCTION}

Thyroid gland dysfunctions in the form of hypo or hyperthyroidism have been known to have a deleterious effect on fertility as well as pregnancy. The various hypofunction thyroid disorders encountered in pregnant women are clinical or clinical and subclinical hypothyroidism. Pregnancy itself modifies thyroid gland functions in the form of $50 \%$ increase in thyroxine (T4) and triiodothyronine (T3) production, decreased levels of thyrotropin (TSH) due to effect of human chorionic gonadotropin and 50\% increase in daily iodine requirement. ${ }^{1}$ Clinical hypothyroidism is defined as decreased free thyroxine levels with an increased value of thyrotropin $(>2.5 \mathrm{miu} / \mathrm{L})$. This has been associated with increased incidence of gestational hypertension and diabetes, preterm delivery and Caesarean section in pregnant women. ${ }^{2}$ This study is undertaken to find out the effects of adequately treated clinical hypothyroidism in pregnancy when compared with pregnant euthyroid controls.

\section{METHODS}

This study was conducted in a tertiary care centre over a period of one year and 144 cases of clinical hypothyroidism in pregnancy were taken into account who formed the case group.

\section{Inclusion criteria}

Newly diagnosed clinical hypothyroidism in pregnancy, $\mathrm{TSH}>2.5 \mathrm{mIU} / \mathrm{L}$ in $1^{\text {st }}$ and $3 \mathrm{mIU} / \mathrm{L}$ in the $2^{\text {nd }}$ and $3^{\text {rd }}$ trimesters respectively according to American thyroid association guidelines. 


\section{Exclusion criteria}

Known case of hypothyroidism in the prepregnancy period. The women in the study group were treated with levothyroxine supplementation and periodically evaluated for adequacy of the treatment by performing thyroid function tests. The control group consisted of 145 age and parity matched euthyroid pregnant women. The parameters studied were development of pregnancy complications like gestational diabetes (GDM), gestational hypertension, oligohydramnios, intrauterine growth restriction and intrauterine foetal demise.

Delivery outcome studied was the occurrence of Caesarean section and it's indication after excluding the previous Caesarean section patients in both the groups. Neonatal outcome studied was the birth weight and necessity for neonatal intensive care. The above parameters were compared between the study and control groups.

\section{RESULTS}

Table 1: Age distribution of hypothyroid pregnant women.

\begin{tabular}{|l|l|}
\hline Age (years) & Number $(\mathbf{n}=\mathbf{1 4 4})$ \\
\hline$<20$ & 2 \\
\hline $21-25$ & 64 \\
\hline $26-30$ & 49 \\
\hline $31-35$ & 27 \\
\hline$>35$ & 2 \\
\hline
\end{tabular}

The total number of clinical hypothyroidism encountered in this one year period is 144 cases which was $6.1 \%$ of the total number of deliveries. In the case group, there were $2(1.4 \%)$ teenage pregnancies and $2(1.4 \%)$ patients were above 35 years of age (Table 1). A total of $29(20 \%)$ patients had a history of previous one or more abortions. There were $19(13.2 \%)$ preterm deliveries out of which 3 were extreme preterm ( $<32$ weeks) and 18 (12.5\%) women delivered post-dated (Table 2).

Table 2: Gestational age at delivery in hypothyroid pregnant women.

\begin{tabular}{|l|l|}
\hline Gestational age (weeks) & Number $(\mathrm{n}=\mathbf{1 4 4})$ \\
\hline$<32$ & 3 \\
\hline $32-36$ & 16 \\
\hline $37-40$ & 107 \\
\hline$>40$ & 18 \\
\hline
\end{tabular}

A total number of 17 patients in the case group developed gestational diabetes mellitus compared to 1 patient in the control group which was statistically significant ( $p$ value $=0.0001$ ). The development of gestational hypertension, oligohydramnios, intrauterine growth restriction and intrauterine demise were comparable in both the groups. $55(38.2 \%)$ patients underwent induction of labour, the commonest indication being prelabour rupture of membranes in 15 cases (Table 3 ).

Table 3: Indications for induction of labour in hypothyroid pregnant women.

\begin{tabular}{|ll|}
\hline Indication & Number $(\mathrm{n}=\mathbf{5 5})$ \\
\hline Prelabour rupture of membranes & 15 \\
\hline $\begin{array}{l}\text { Preterm prelabour rupture of } \\
\text { membranes }\end{array}$ & 3 \\
\hline Oligohydramnios & 14 \\
\hline Post dated & 6 \\
\hline Gestational hypertension & 2 \\
\hline $\mathrm{Rh}$-ve & 3 \\
\hline Intrauterine demise & 4 \\
\hline Decreased foetal movement & 6 \\
\hline Gestational diabetes & 1 \\
\hline Anomalous foetus & 1 \\
\hline
\end{tabular}

Regarding the delivery outcome, $73(50.7 \%)$ patients delivered vaginally (Table 4). The rates of Caesarean section in both groups were similar but a significantly higher number of patients underwent Caesarean section for the indication of foetal distress in the case group ( $p$ value $=0.00002)($ Table 5).

Table 4: Mode of delivery in hypothyroid women.

\begin{tabular}{|l|l|}
\hline Mode of delivery & Number $(\mathrm{n}=\mathbf{1 4 4})$ \\
\hline Normal vaginal & 68 \\
\hline Instrumental vaginal & 5 \\
\hline Emergency Caesarean & 45 \\
\hline Elective Caesarean & 26 \\
\hline
\end{tabular}

Table 5: Comparison between hypothyroid and euthyroid pregnant women.

\begin{tabular}{|llll|}
\hline Parameter & $\begin{array}{l}\text { Study group } \\
\text { (hypothyroid) } \\
\text { n= 144 }\end{array}$ & $\begin{array}{l}\text { Control } \\
\text { group } \\
\text { (euthyroid) } \\
\text { n= 145 }\end{array}$ & P value \\
\hline $\begin{array}{l}\text { Gestational } \\
\text { diabetes }\end{array}$ & 17 & 1 & 0.00001 \\
\hline $\begin{array}{l}\text { Gestational } \\
\text { hypertension }\end{array}$ & 13 & 14 & 0.86 \\
\hline Oligohydramnios & 21 & 16 & 0.37 \\
\hline $\begin{array}{l}\text { Intrauterine } \\
\text { growth } \\
\text { restriction }\end{array}$ & 2 & 3 & 0.66 \\
\hline $\begin{array}{l}\text { Intrauterine } \\
\text { foetal demise }\end{array}$ & 3 & 5 & 0.5 \\
\hline $\begin{array}{l}\text { Caesarean } \\
\text { section }\end{array}$ & 45 & 43 & 0.77 \\
\hline Foetal distress & 33 & 8 & 0.00002 \\
\hline $\begin{array}{l}\text { Large for } \\
\text { gestational age } \\
\text { baby }\end{array}$ & 25 & 15 & 0.84 \\
\hline
\end{tabular}


There was an association of large for gestational age babies in the case group as compared to the control group, 25 babies had a birth weight of more than $3.5 \mathrm{~kg}$ in the former group compared to 15 babies in the latter group. The need for neonatal intensive care unit was similar in both the groups.

\section{DISCUSSION}

The incidence of hypothyroidism in pregnancy was found to be $6.3 \%$ in an Indian study with clinical hypothyroidism being $2.9 \%$ whereas in the present study it was found to be $6.1 \%{ }^{3}$ Age more than thirty years was not found to be associated with maternal hypothyroidism in the study conducted by Potlukova et al which was similar to the present study where only $20 \%$ cases belonged to that age group. ${ }^{4}$

In a study conducted on pregnant women in Bangladesh, hypothyroidism was associated with development of gestational diabetes. ${ }^{5}$ In another study by Mannisto et al it was observed that hypothyroid pregnant women have increased odds for developing this complication. ${ }^{2}$ Hypothyroidism in pregnancy was more frequently associated with gestational diabetes in a study by Gudovic et al whereas no association was found in another study conducted in Turkey by Kumru et al. ${ }^{6,7}$ In the present study there was a statistically significant number of gestational diabetes in the case group compared to controls $(\mathrm{p}=0.00001)$.

There is conflicting evidence regarding development of pregnancy induced hypertension in pregnant patients with hypothyroidism. In the study by Sharmeen et al there was a positive association which was similar to another study by Nazarpour et al in Iran. ${ }^{5,8}$ Increased association was also found in the study by Mannisto et al between hypothyroidism in pregnancy and preeclampsia as well by Goel et al. ${ }^{2,3}$ No association with hypertensive disorders were found by Medici et al as well as by Kumru et al. ${ }^{7,9}$ Similar results were reported in the study by Gudovic et al. ${ }^{6}$ In this study there was no increased association for the development of hypertension in the case and control groups.

In a study conducted by Hirsch et al premature deliveries was found to be $2.9 \%$ in clinical hypothyroid women ${ }^{[10]}$. Preterm deliveries were found to be higher in studies by Kumru and Nazarpour et al in studies conducted in Turkey and Iran respectively. ${ }^{7,8}$ Increased risk was also reported by Saki et al as well as by Mannisto et al. ${ }^{2,11}$ The present study also showed similar results as there were $13.2 \%$ preterm deliveries.

In a study in United states by Mannisto et al, Caesarean section rates were higher in pregnant women with hypothyroidism. $^{2}$ A higher association of Caesarean deliveries was found between hypothyroid women with concurrent gestational diabetes by Tirosh et al as well as by Stohl et al. ${ }^{12,13}$ However, in the Turkish study by
Kumru et al, no association was found between thyroid dysfunction and Caesarean section rates. ${ }^{7}$ In this study, though the Caesarean rates were not significantly higher in the study group compared to the control, but there was a statistically significant number of Caesarean sections being done for the indication of foetal distress $(\mathrm{p}=0.00002)$ with $18.7 \%$ deliveries complicated by meconium stained liquor.

Intrauterine demise was found to be higher in hypothyroid group in a study by Nazarpour et al. ${ }^{7}$ Intrauterine growth restriction was reported to be associated with clinical hypothyroidism in the study by Sharmeen et al. ${ }^{5}$ In this study, there was no association of intrauterine growth restriction and foetal demise with hypothyroidism.

Regarding neonatal outcome, both Kumru et al and Nazarpour et al has reported a higher incidence of low birth weight babies in mothers with clinical hypothyroidism. ${ }^{7,8}$ However in our study, a higher number of large for gestational age babies were noted in the study group when compared to the control group $(p=0.0836)$. Similar results were reported in hypothyroid non-Hispanic white women in an American study. ${ }^{14}$

\section{CONCLUSION}

Clinical hypothyroidism in pregnancy, even though adequately treated with levothyroxine supplementation may lead to complications like gestational diabetes, preterm deliveries and a higher rate of Caesarean sections for foetal distress. Large for gestational age neonates are more common in mothers with clinical hypothyroidism compared to pregnant euthyroid controls.

\section{ACKNOWLEDGEMENT}

Authors would like thanks to Dr. G Ezhumalai, Senior statistician and research consultant, SBV University.

Funding: No funding sources

Conflict of interest: None declared

Ethical approval: The study was approved by the Institutional Ethics Committee

\section{REFERENCES}

1. Alex SG, Marcos A, Erik A, Fereidoun A, Jorge M, Roberto N. Guidelines of the American thyroid association for the diagnosis and management of thyroid disease during pregnancy and postpartum. Thyroid. 2011;21(10):1081-11.

2. Mannisto T, Mendola P, Grewal J, Xie Y, Chen Z, Laughon SK. Thyroid diseases and adverse pregnancy outcomes in a contemporary US cohort. J Clin Endocrinol Metab. 2013;98(7):2725-33.

3. Goel P, Kaur J, Saha PK, Tandon R, Devi L. Prevalence, associated risk factors and effects of 
hypothyroidism in pregnancy: a study from North India. Gynecol Obstet Invest. 2012;74(2):89-94.

4. Potlukova E, Potluka O, Jiskra J, Limanova Z, Telicka Z, Bartakova J. Is age a risk factor hypothyroidism in pregnancy? An analysis of 5223 pregnant women. J Clin Endocrinol Metab. 2012;97(6):1945-52.

5. Sharmeen M, Shamsunnahar PA, Laita TR, Chowdhury SB. Bangladesh Med Res Counc Bull. 2014;40(2):52-7.

6. Gudovic A, Spremovic- Radjenovic S,Lazovic G, Marinkovic J, Glisic A, Millicevic S. Maternal autoimmune thyroid disease and pregnancy complication. Vojnosanit Pregl. 2010;67(8):617-21.

7. Kumru P, Erdogdu E, Arisoy R, Demirci O, Ozkoral A, Ardic C. Effect of thyroid dysfunction and autoimmunity and pregnancy outcomes in low risk population. Arch Gynecol Obstet. 2015;291(5):104754.

8. Nazarpour S, Ramezani Teherani F, Simbar M, Azizi F. Thyroid dysfunctions and pregnancy outcomes. Iran J Reprod Med. 2015;13(7):387-96.

9. Medici M, Korevaar T, Schalekamp-Timmermans S, Gaillard R, de Rijke YB, Visser WE. Maternal early pregnancy thyroid function with subsequent hypertensive disorders of pregnancy: the generation R studies. J Clin Endocrinol Metab. 2014;99(12):2591-8.

10. Hirsch D, Levy S, Nadler V, Kopel V, Shainberg B, Toledano Y. Pregnancy outcomes in women with severe hypothyroidism. Eur $\mathrm{J}$ Endocrinol. 2013;169(3):313-20.

11. Saki F, Dabbagmanesh MH, Ghaemi SZ, Forouhari S, Ranjbar Omrani G, Bakhshayeshkaram M. Thyroid function in pregnancy and it's influences on maternal and fetal outcomes. Int J Endocrinol Metab. 2014;12(4):19378.

12. Tirosh D, Benshalom-Tirosh M, Novack L, Press F, Beer-Weisel R, Wiznitzer A. Hypothyroidism and diabetes mellitus - a risky dual gestational endocrinopathy. Peer J. 2013;19;1:e52.

13. Stohl L, Ouzounian J, Rick AM, Hueppchen NA, Bienstock JL. J Matern Fetal Neonatal Med. Thyroid disease and gestational diabetes mellitus (GDM): is there a connection? 2013;26(11):1139-42.

14. Mannisto T, Mendola P, Reddy U, Laughon SK. Neonatal outcomes and birth weight in pregnancies complicated by maternal thyroid disease. Am J Epidemiol. 2013;178(5):731-40.

Cite this article as: Lopamudra JB, Reddi RP, Ghose S. Outcome of clinical hypothyroidism in pregnancy: a case control study. Int J Reprod Contracept Obstet Gynecol 2016;5:1996-9. 